\title{
Building performance based on measured data
}

\author{
S. Andersson ${ }^{1, *}$, J-U Sjögren ${ }^{2}$, R. Östin ${ }^{1}$ and T.Olofsson ${ }^{1}$ \\ 1. Department of applied physics and electronics, Umeå, Sweden \\ 2. NCC Ltd, Stockholm, Sweden \\ *Corresponding Author Tel: +46-9078679 45; E-mail staffan.andersson@tfe.umu.se
}

\begin{abstract}
With increasing liability for builders, the need for evaluation methods that focuses on the building's performance and thus excludes the impact from residents' behavior increases. This is not only of interest for new buildings but also when retrofitting existing buildings in order to reduce energy end-use.
\end{abstract}

The investigation in this paper is based on extensive measurements on two fairly representative type of buildings, a single family building in Ekerö, Stockholm built 2000 and two apartment buildings in Umeå (1964) in order to extract key energy performance parameters such as the building's heat loss coefficient, heat transfer via the ground and heat gained from the sun and used electricity.

With access to pre-processed daily data from a 2 -month periods, located close to the winter solstice, a robust estimate of the heat loss coefficient was obtained based on a regression analysis. For the single family building the variation was within $1 \%$ and for the two heavier apartment buildings an average variation of $2 \%$, with a maximum of $4 \%$, between different analyzed periods close to the winter solstice.

The gained heating from the used electricity in terms of a gain factor could not be unambiguously extracted and therefore could only a range for the heat transfer via ground be estimated. The estimated range for the transfer via ground for the two apartment buildings were in very good agreement with those calculated according to EN ISO 13370 and corresponded to almost $10 \%$ of the heating demand at the design temperature. For the single family building with an insulated slab and parts of the walls below ground level, the calculations gave slightly higher transfer than what was obtained from the regression analysis. For the estimated gained solar radiation no comparison has been possible to make, but the estimated gain exhibited an expected correlation with the global solar radiation data that was available for the two apartment buildings.

Keywords: Regression analysis, Heat loss coefficient, Heat transfer via ground, Gained heat

\section{Nomenclature}

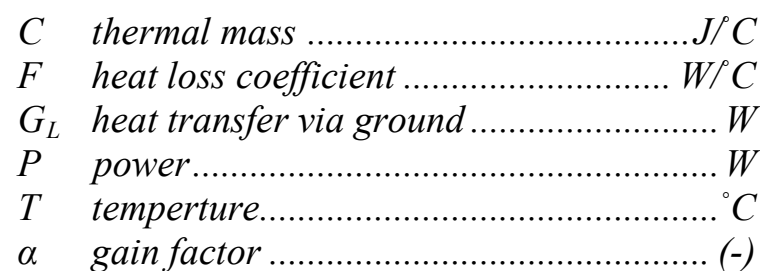

Indices

d dynamic heat storage

el electricity

\section{Introduction}

Energy performance assessment [1] is normally done by energy consumption calculations, estimations based on energy bills, extensive measurements [2-4] or a combination of these methods. Assessments that are based on extensive measurements are often done by identifying the parameters of the used model The used models may basically be divided in two groups, dynamic or static, and where the overall heat loss coefficient is a commonly used performance parameter. 
With increased demands, that new or renovated building meet promised performance, the demands on validation but also on the used energy consumption calculations in the design stage increases. Today, in Sweden, a buildings energy performance usually is expressed in terms of energy use per square meter heated area. The problem with this performance measure is that only a part of the supplied energy is considered, i.e energy directly used for space heating and domestic hot water preparation together with electricity used for the buildings technical systems and common areas. Contributions related to user behaviors such as household electricity, indoor temperature and personal heating are not included together with the contribution from solar radiation.

The objective behind this work is to investigate the possibility to, based on extensive measurements, extract the thermal performance parameters that describes the building itself and where the contributions from the users and the sun are filtered out. This has great significance for a buyer or seller/manufacturer from liability point of view, since the behavior of the building itself is the only thing a seller/manufacturer can guarantee.

\section{Methodology}

Measurements have been carried out during a year (March 2009-March 2010) in two types of buildings, a single family building outside, Stockholm (built 2000) and two apartment buildings in northern Sweden, Umeå. The apartment buildings (\#1 and \#2), were built 1962 with 12 a nd 9 apartments, respectively. Common for all studied objects, are an exhaust ventilation system with a fan operating at a constant speed and no heat recovery and that they are connected to district heating.

Extensive measurements of indoor and outdoor temperatures, used district heating for domestic hot water and heating as well as the total electricity use (households and electricity for the technical systems). In addition, the global solar irradiation has been measured in the near vicinity of the two apartment buildings located in Umeå.

To analyze the energy use, we have used average daily values together with a simplified power balance of a building. In the results presented here, the indoor temperature was taken to be the exhaust air temperature. The main simplification lies in the fact that the effects of wind are not considered together with any impact from humidity and that the heat loss coefficient between indoor and external temperature has been taken to be constant. The latter assumption is based on a constant operation of the exhaust fan in each building. Based on $t$ hese simplifications the power balance of a building could be described by

$P_{h}+\alpha P_{e l}+P_{p}+P_{s}+P_{w}=F\left(T_{i}-T_{o}\right)+G_{L}+P_{d}$

with $P_{d}=C \frac{T_{d}}{d t}$ and where $T_{d}$ is the temperature of the thermal mass.

The contributions to heating from the sun, $P_{s}$, gained heat or heat loss due to domestic hot and cold water usage $P_{w}$, contribution from body heat, $P_{p}$, together with the dynamic heat storage, $P_{d}$, is very difficult to measure. These parameters of Eq. 1 have been treated in the following way.

$P_{s}$ : Experimental data from periods around the winter solstice has been used, in order to minimize contribution from solar radiation when determining the heat loss coefficient, $\mathrm{F}$ 
$P_{w}$ : Assumed that the heat transfer from the domestic hot water circulation equals the heating of domestic cold water.

$P_{p}$ : Based on data from a survey, the contribution to heating was assessed from the number family members and their presence at home.

$P_{d}$ : Two different approaches A and B for pre-processing measured data have been used to minimize this contribution.

A) Averaging over a time period longer than the estimated time constant of each building.

B) Averaging over two days, that has an estimated equal change of $T_{d}$ in magnitude but in opposite direction. For an ideal building that has a constant indoor room temperature and is not exposed to solar radiation, the dynamic heat storage could be eliminated by taking the average over two days for which the change in outdoor temperature are equal but opposite, for instance +5 and $-5{ }^{\circ} \mathrm{C}$. Based on this approach, an estimate of the change in the temperature of the buildings thermal mass, $\Delta T_{d}$, was taken to be represented by the change in $\frac{T i+T o}{2}+\omega T_{i}$ be tween two consecutive days. The weight factor, $\omega$, between the two terms should be used in relation to the thermal mass the two terms represent.

The advantage with B) is that the number of data is only reduced by approximately half, whereas an averaging over a time period longer than the time constant of a heavy building may reduce available data to a degree that a regression analysis becomes hazardous.

Thermal performance measures, such as the heat loss factor, ground transfer and contribution from solar radiation and gained heating from electricity has been estimated by a 1 inear regression analysis but also the sensitivity of these parameters to the choice of indoor temperature, length of analyzed period, variation in ambient temperature etc. For a full description, see [5].

\section{Results}

A basic approach in this work is to use the period of the year when the contribution from the solar radiation is smallest, in order to simplify Eq. (1). In Figure 1 below, the measured global solar radiation is shown. The measurements are made at Umeå University which is in the close vicinity of the two apartment buildings, less than one kilometer.

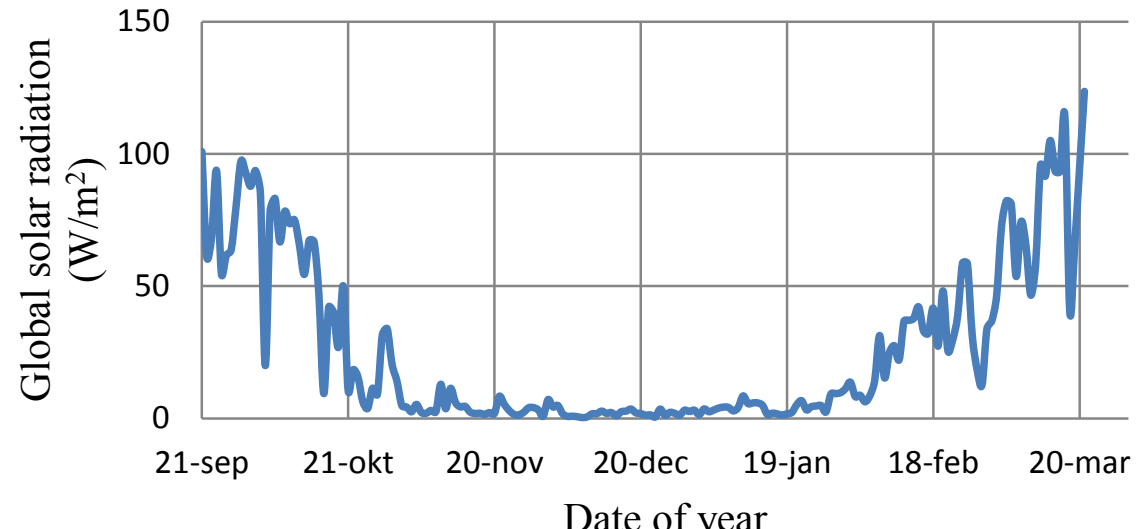

Fig. 1. Global solar radiation, measured at Umeå University

When analyzing data from periods around the winter solstice (December 21: st), the contribution $P_{s}$ is negligible according to Figure 1. Together with $P_{w}=0$ and using pre- 
processed data to minimize the dynamic heat storage, Eq. (1) simplifies to

$P_{h}+\alpha P_{e l}+P_{p}=F\left(T_{i}-T_{o}\right)+G_{L}$

With access to measured data of $P_{h}$ and $P_{e l}$ together with $P_{p}$ based on a survey, Eq. (2) becomes

$P_{t}=F\left(T_{i}-T_{o}\right)+(1-\alpha) P_{e l}+G_{L}$

Where $P_{t}=P_{e l}+P_{h}+P_{p}$.

The total electricity use, $P_{e l}$, is a parameter of Eq. (3) and in Figure 2 below, data from the period 1 November to February 6 is presented versus $\left(T_{i}-T_{o}\right)$. The data have been preprocessed according to B).

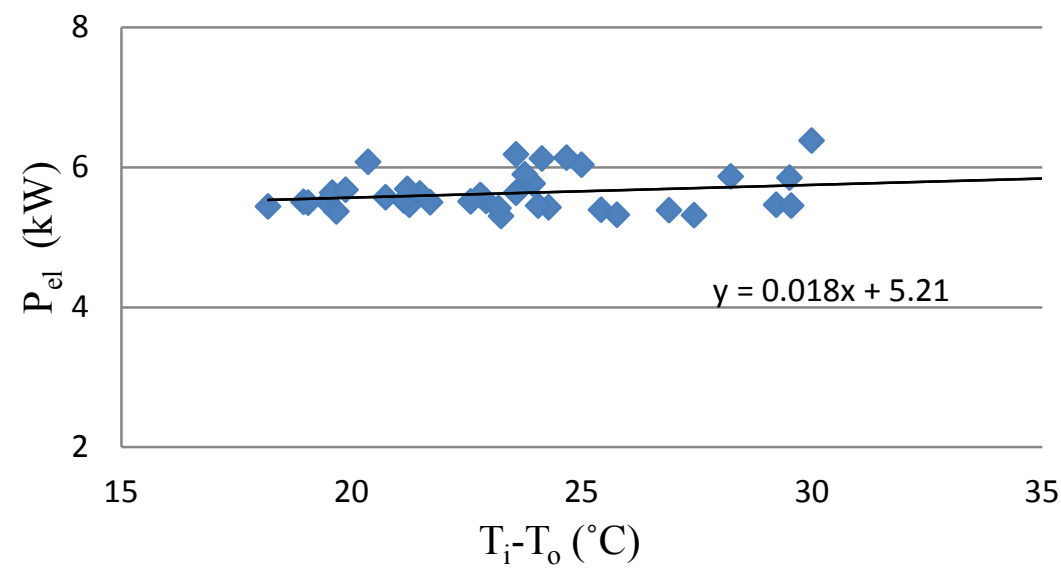

Fig.2. $P_{\text {el }}$ versus $\left(T_{i}-T_{o}\right)$ for building \#1 together with a linear regression

As seen from Figure 2 the measured total use of electricity is fairly constant and may, with a fairly good accuracy be represented by a linear function of $\left(T_{i}-T_{o}\right)$. The pre-processing of data (according to B) reduces strongly the daily variation of $P_{e l}$ and yields similar results as pre-processing by averaging daily data over a period longer than the time constant. This behavior is found for both apartment buildings as well as the single family building.

If $P_{e l}$ may be described as

$P_{e l}=P_{e l, 0}+k\left(T_{i}-T_{o}\right)$

a linear regression according to

$P_{t}=F_{t}\left(T_{i}-T_{o}\right)+P_{t, 0}$

would, based on Eq. (3) yield the following relation between $F$ and $F_{t}$ according to

$F=F_{t}-(1-\alpha) k$

based on the assumption that the heat transfer via ground is constant during the analyzed period and that gain factor, $\alpha$, also is fairly constant. Since $k$ in Eq. (4) is small (Figure 2), the 
impact on the value of $F_{t}$, determined by a linear regression according to Eq. 5 is very small. This means that $\alpha$ may be treated as constant, but also that $F \cong F_{t}$ since $k$ is small and $\alpha$ is expected to be closer to unity than zero.

The following alternatives for pre-processing data according to A) and B) were investigated.

$\mathrm{A} n$ : Average over $n$ consecutive days, where $\mathrm{n}$ is between four days (A4) for the single family building and six days (A6) for the apartment buildings.

B1: Apartment buildings: Since the estimated thermal mass is fairly equal for the climate shell and the internal walls, $\omega$ was taken to be equal to 1 and thus was $\Delta T_{d}$ taken as the change of $\left(T_{i}+T_{o}\right) / 2+T_{i}$ between two consecutive days.

B2: Single family building. Since the internal walls were light, $\omega$ was taken to zero, and thus $\Delta T_{d}$ was calculated as the change of $\left(T_{i}+T_{o}\right) / 2$ between two consecutive days.

A linear regression according to Eq. (5) (Building \#1 for the period 1 November to February 6) are presented in Figure 3. Data has been pre-processed according to B6.

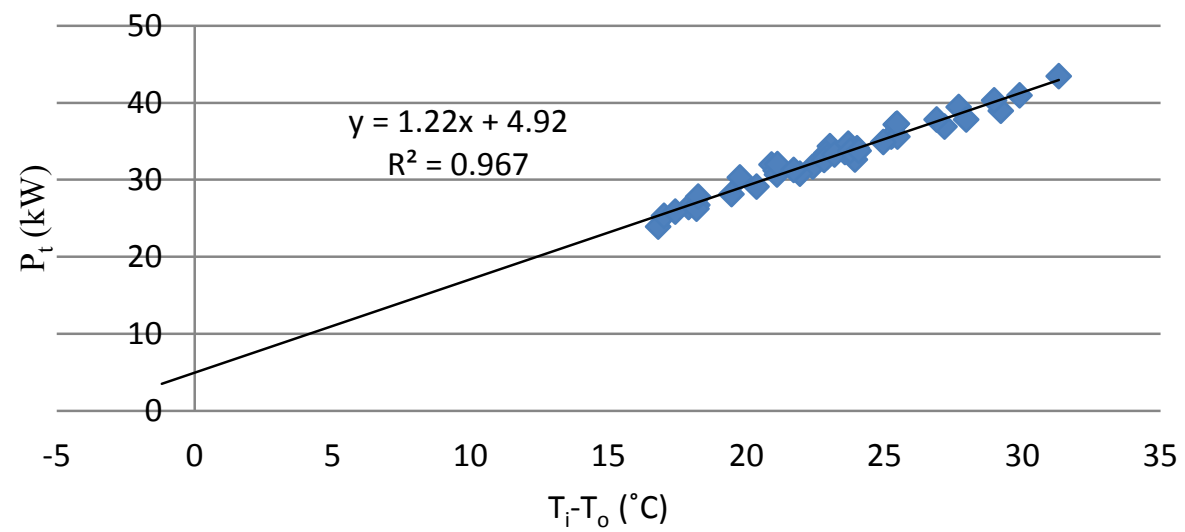

Fig. 3. $P_{t}$ versus $\left(T_{i}-T_{o}\right)$ for building \#1. The data are from the period, 1 November to 6 February 6 , and the data has been preprocessed according to B6.

The results in Figure 3 support the assumption of a constant heat loss coefficient. In table 1, the results based on a regression analysis (Eq. 5) for all investigated buildings are compiled for time periods of two month around the winter solstice using different pre-processing techniques.

For the two apartment buildings, as seen in table 1, the variation in the estimate of $F_{t}$ is reduced when using pre-processing of data according to B1 than compared to A6, with an average variation of $2 \%$, and a maximum of $4 \%$, between different analyzed periods close to the winter solstice. For the single family building the variation is within $1 \%$ for both methods of pre-processing data.

Besides $F_{t}$, the regression analysis also gives the intercept, see Figure 3, w hich could correspond to the heat transfer via ground during that period. But $P_{t}$ includes the total electricity use, $P_{e l}$, and the contribution to heating is only $\alpha P_{e l}$, where $0 \leq \alpha \leq 1$. This means that the for the case shown in fig. 4, the intercept $P_{t, 0}=4.9 \mathrm{~kW}$ should be reduced with (1$\alpha) \cdot P_{e l, 0}$ to obtain an estimate of the heat loss via ground, $G_{L}$.

Besides $F_{t}$, the regression analysis also gives the intercept, see Figure 3, w hich could correspond to the heat transfer via ground during that period. But $P_{t}$ includes the total electricity use, $P_{e l}$, and the contribution to heating is only $\alpha P_{e l}$, where $0 \leq \alpha \leq 1$. This means 
that the for the case shown in fig. 4, the intercept $P_{t, 0}=4.9 \mathrm{~kW}$ should be reduced with (1$\alpha) \cdot P_{e l, 0}$ to obtain an estimate of the heat loss via ground, $G_{L}$.

Table 1. Compilation of the results based on a two month period, with different schemes for preprocessing experimental data. The relative deviation from the average value is given within brackets. For the apartment buildings the results are also given for the longest period when the measured global radiation was less than $20 \mathrm{~W} / \mathrm{m}^{2}$.

\begin{tabular}{|c|c|c|c|}
\hline & & $F_{t}\left[\mathrm{~kW} /{ }^{\circ} \mathrm{C}\right]$ & \\
\hline & & Building \#1 & \\
\hline Pre-proce & & A6 & B1 \\
\hline 2-month & $21 / 11-21 / 1$ & $1.34(6 \%)$ & $1.23(1 \%)$ \\
\hline & $1 / 11-31 / 12$ & $1.22(-3 \%)$ & $1.24(2 \%)$ \\
\hline & $1 / 12-31 / 1$ & $1.22(-3 \%)$ & $1.19(-3 \%)$ \\
\hline $\bar{F}_{t} 2$-mon & & 1.26 & 1.22 \\
\hline & $1 / 11-6 / 2$ & 1.26 & 1.22 \\
\hline & & Single famil & building \\
\hline Pre-proce & & A4 & B2 \\
\hline 2-month & $21 / 11-21 / 1$ & $0.150(1 \%)$ & $0.148(-1 \%)$ \\
\hline & $1 / 11-31 / 12$ & $0.146(-1 \%)$ & $0.150(1 \%)$ \\
\hline & $1 / 12-31 / 1$ & $0.149(0 \%)$ & $0.149(0 \%)$ \\
\hline $\bar{F}_{t} 2$-mont & & 0.148 & 0.149 \\
\hline
\end{tabular}

The value of $\alpha$, is difficult to determine from available data. Method by using multivariate regression (PLS) $[6,7]$ have been examined, but due to the fact that $P_{e l}$ behave very "nice" and is correlated to $\left(T_{i}-T_{o}\right)$, the uncertainty in the determination of $\alpha$ becomes very large and no clear estimates could be obtained. Of the actual electricity use in building \#1, hous ehold electricity constitutes about $70 \%$ and the remaining 30\% for lighting outdoors and for common areas and for the exhaust fan that is situated under the roof and thus out-side the climate shell. An approximate estimates of $\alpha$, yield a value between 0.6 and 0.8 . Based on this, the heat transfer via ground is estimated to be in the range of 2.9 and $3.9 \mathrm{~kW}$. With access to measurements of the basement temperature of building $\# 1, t$ he design of the building and the fact that the building is situated on a former sea bottom, calculation of the heat transfer via ground was performed according to EN-ISO-13370, se Figure 5.

Calculated heat loss for building \#1, $(\mathrm{kW})$

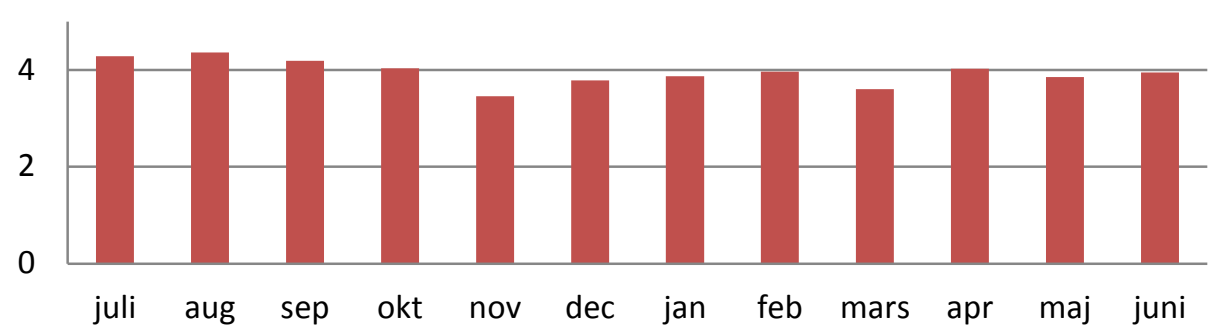

Fig.4. Calculated monthly heat loss via ground according to EN-ISO-13370, clay soil.

Figure 4 shows that the calculated heat transfer via ground both on an annual basis and for the periods analyzed are relatively constant and in good agreement with the estimated transfer of 2.9-3.9 $\mathrm{kW}$ for the time period closed to the winter solstice. 
If the heat transfer via ground are constant over the year, the utilized solar radiation for heating, $P_{s}$, may be estimated, based on a constant heat loss coefficient, $F$. The results for building \#1, are displayed in Figure 6 for the entire measured period assuming a constant level of the heat transfer via ground. The data presented in Figure 5 consists of daily data from 1 January to 31 March of 2010 and 1 April to 31 December 2009 and hence the step in the graph.

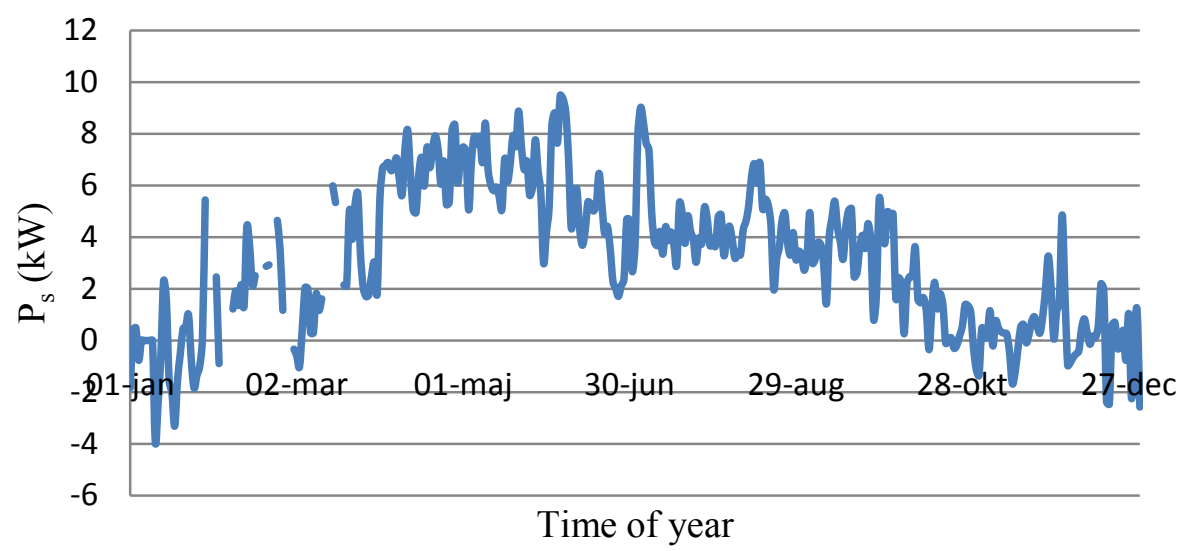

Fig. 5. Estimated gained heat from solar radiation, building \#1.

At the beginning and end of the year, $P_{s}$ fluctuates around zero. The main reason behind this is the use of daily data, and the variation thus reflects dynamic heat storage. If data were preprocessing according to B6, these fluctuations would be reduced, but at the same time, data could not be present in this way since time loses its meaning. The fact that $P_{s}$ is lower than expected around the summer solstice is probably explained by the Swedish tradition to have open doors and windows during our short but cherished summer.

Since the theoretical calculations of the monthly heat transfer via ground, for the single family building indicated a fairly large variation over the year, a similar analysis is not possible. But based on an estimate of $0.6 \leq \alpha \leq 0.8$ ], an estimated range for the heat transfer via ground, during the 2-month period of $0.22 \mathrm{to} 0.39 \mathrm{~kW}$ was obtained, to be compared with the calculated $0.5 \mathrm{~kW}$ for this split level building. Since the heat transfer via ground has a strong variation over the year, could only the difference between gained solar radiation and heat transfer via ground be estimated, $\left(P_{s}-L_{G}\right)$, if $\alpha$ is known and constant. With $\alpha=0.7$, the results shown in Figure 6 was obtained. For the single family building, only incomplete data was available for the summer period and are thus missing in Figure 6.

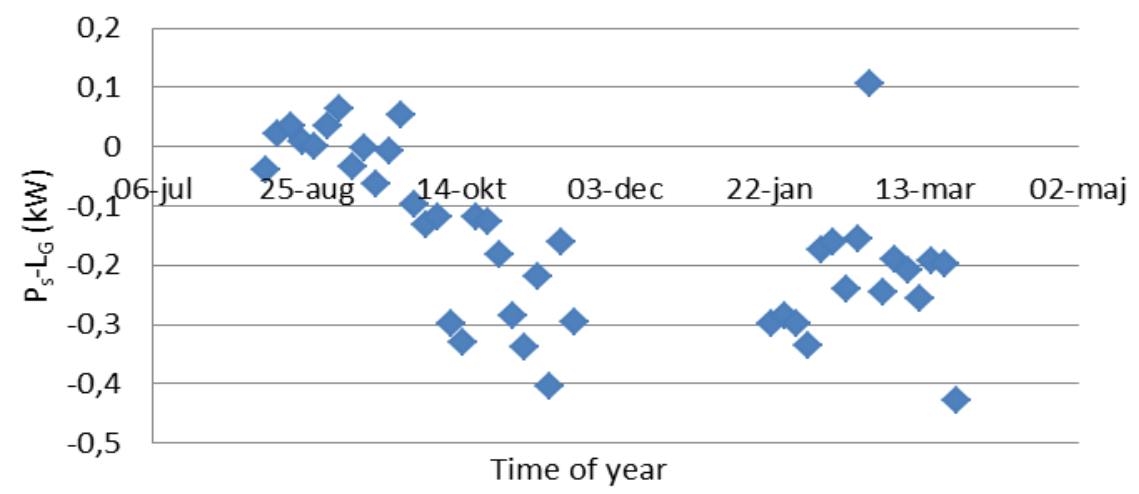

Fig. 6. Estimated $P_{\text {sol }}-L_{G}$ over the period where measured data was available. 
Figure 6, indicates that the contribution to heating from solar radiation exceeds the heat transfer via ground until the beginning of October and this situation is reversed in the end of March.

\section{Discussion}

In this work we have used experimental data from time periods close to the winter solstice and data has been pre-processed to reduce dynamic heat storage effects. Based on this and with access to extensive measurements, the heat loss factor has been determined with a high precision for the investigated buildings. Unfortunately, a fundamental problem remains; no correct answer is available for the heat loss coefficient as reference.

However, based on the high precision and the fact that the obtained estimate of the heat transfer via ground are in good agreement with calculations based on ISO-EN-13370 indicates that the used approach gives consistent results. In addition, the estimated gained solar radiation, of Figure 4, increases in a basically linear way when plotted versus the global solar radiation. This means that the obtained results could be used as feedback to energy calculations.

The buildings investigated in this study have a simple HVAC-system and the next step is therefor to extend this work to more energy efficient buildings with complex systems and also to focus on methods to obtain an estimate of the gain factor $\alpha$ for the electricity use. This could be achieved by a close survey of where and for what the electricity has been used or using multivariate methods or artificial neural networks $[8,9]$.

\section{References}

[1] ASHRAE Handbook Fundamentals 2005, Atlanta, USA

[2] F.W. Yu and K.T. Chan, Energy signatures for assessing the energy performance of chillers, Energy and Buildings, 2005 Vol. 37 (7), pp. 739-746.

[3] C. Ghiaus, Experimental estimation of building energy performance by robust regression, Energy and Buildings, 2006 Vol. 38(6), pp. 582-587

[4] A Rabl and R Rialhe, Energy signature models for commercial buildings: test with measured data and interpretation, Energy and buildings, 1992 Vol. 10, pp.143-154.

[5] S. Andersson, J-U. Sjögren, $\mathrm{T}$ Olofsson and R Östin, Prestanda- och beteendeuppföljning av byggnaders energianvändning. 2010, Internal report. Dept. of Applied Physics and Electronics, Umeå University

[6] S Wold, M Sjöström and L Erikson, PLS-regression: A basic tool of chemometrics, Chemometrics and intelligent laboratory systems, 2001 Vol. 58, pp 109-130

[7] T Olofsson, S Andersson and J-U Sjögren, Building energy parameter investigations based on multivariate analysis, Energy and Buildings, 2009 Vol. 41(1), pp. 71-80

[8] M Lundin, S Andersson, R Östin A.R. Further validation of a method aimed to estimate building performance parameters, Energy and Buildings, 2005 Vol.37 (8), pp. 867-871

[9] P.A. Gonza'lez, J.M. Zamarreño, Prediction of hourly energy consumption in buildings based on a feedback artificial neural network, Energy and Buildings 2005 Vol. 37(6) pp. 595-601. 